Check for updates

Cite this: RSC Adv., 2017, 7, 45034

\section{Bio-inspired electrochemical corrosion coatings derived from graphene/natural lacquer composites}

\author{
Yajun Deng, ${ }^{a}$ Weibin Bai, ${ }^{\text {ab }}$ Jipeng Chen, ${ }^{a}$ Xinmei Zhang, ${ }^{a}$ Shenji Wang, ${ }^{a}$ Jinhuo Lin ${ }^{\text {ab }}$ \\ and Yanlian Xu (D)*ab
}

Protective corrosion coatings are preferably composed of available, environmentally friendly, and low-volatility organic compounds. Herein, new excellent corrosion graphene/raw lacquer composite coatings were formed, in which waterborne graphene was modified by taking lignin tripolymer (LT) as an aqueous stabilizer and subsequently adding to raw lacquer (RL). Graphene/lacquer composite coatings were achieved by an ecofriendly fabrication process. The structure and thermostability of the lignin derivative were studied by Fourier transform infrared spectroscopy (FT-IR) and thermogravimetry (TG), respectively, while the composition of the LT was characterized by Raman spectrometry. And the experimental result revealed that LT was an effective graphene dispersant (LTG) up to $60 \mathrm{~d}$ without any precipitation. Besides, the SEM of the graphene/lacquer coatings revealed that the excellent protection properties were highly attributable to the formation of a very rough surface, because of the highly dispersed nature of the graphene nanoparticles. Also, the corrosion behavior of the composite coatings on a metal substrate were studied by polarization curve analysis and electrochemical impedance spectroscopy (EIS). According to the electrochemical corrosion tests, the lacquer composite coating with 5 wt\% LTG dispersion (RL/LTG-5, containing 0.3 wt\% graphene) possessed excellent corrosion resistance, making it suitable for protecting bare metal substrates.
Received 2nd August 2017

Accepted 12th September 2017

DOI: $10.1039 / c 7 r a 08536 b$

rsc.li/rsc-advances materials $^{8}$ etc. However, due to strong van der Waals forces between layers, graphene is so easy to aggregate that has challenged to disperse and limit the scope of further applications. ${ }^{9-11}$ Numerous approaches have been recently developed in using graphene as a highly dispersed anti-corrosion inhibitor. For example, Lin $\mathrm{Gu}$ et al. synthesized a waterborne carboxylated aniline trimer derivative used as a stabilizer to disperse commercial water-based graphene. This stabilized graphene dispersion was added to epoxy resin to improve its anticorrosive properties. ${ }^{12}$ Peng He et al. developed graphene quantum dots (GQDs) as effective dispersants of commercial graphene. And flexible graphene sheets directly assembled from water-dispersible graphene exhibited controllable thickness, acceptable strength, and good conductivity. ${ }^{13}$ Through the interaction of hydrogen bones to disperse graphene, lignin is an another green material choose that have a number of advantages including recyclable natural resource, low-cost treatment, biodegradability, and lack of heavy metals or other toxic substances causing great harm to the environment. ${ }^{14,15}$ It is easy to modify lignin due to complex chemical compound comprised of various functional frameworks based on ether and aliphatic hydrocarbons. ${ }^{16-19}$ And great efforts have been recently made in developing lignin materials through those groups. ${ }^{20-22}$ For example, Hoyong Chung et al. found that Lewis acidfunctionalized lignin possessed a higher concentration of hydroxyl groups $(-\mathrm{OH})$ available to react with diisocyanate monomers, thereby demonstrating that the properties of
${ }^{a}$ College of Material Science and Engineering, Fujian Normal University, Fuzhou 350007, PR China. E-mail: ylxu@fjnu.edu.cn; Fax: +86 59183165668; Tel: +86 59183443871

${ }^{b}$ Fujian Key Laboratory of Polymer Materials, Fuzhou 350007, PR China 
lignin-based polymeric materials can be significantly improved. ${ }^{23}$ Wanshuang Liu et al. prepared carboxylic acidfunctionalized alkali lignin (AL-COOH) and subsequently added it to anhydride-cured epoxy networks via a one-pot method. Mechanical tests revealed that the addition of rigid AL-COOH resulted in toughened epoxy matrix materials without any additional external effect. ${ }^{24}$ In the sense, it is an eco-friendly and significative study that modified lignin offer an alternative way to recycle and it is as stabilizer to disperse graphene.

The health and environmental risks, as well as the high cost of corrosion, would been taken into account when developing a new corrosion coating. As an alternatives, environmentally friendly coatings, nowadays, have received increased attention as metal protection systems in view of the low utilization of volatile organic compounds (VOCs) and low pollution characteristics of this technology. ${ }^{25-27}$ And raw lacquer is the natural product coating with a high solid content. It is highly available in East and Southeast Asia, and China is the largest lacquer producer. Because of lacasse, an oxidoreductase, raw lacquer can be dried under natural conditions via enzymatic oxidation of urushiol, and autoxidation of urushiol generates unsaturated side chains. $^{28,29}$ In this sense, lacquer have good properties including durability, impermeability, and chemical resistance to oxygen, water, and chloride ion as a natural coating. ${ }^{30-34}$ During the previous decades, $\mathrm{Hu}$ and Lin have reported that urushiol-metal polymers by the reaction between metal ion and the hydroxyl groups on the phenyl ring of urushiol..$^{35-41}$ And the urushiolmetal polymers could be dried in the natural environment without laccase catalysis. Moreover, the properties of urushiolmetal polymers were excellently improved such as resistance against chemical media, against alkali, and thermal stability. ${ }^{42}$ In fact, the urushiol-metal polymers have employed as industrial production and used as a heavy anticorrosive coating in chemical industry in China. ${ }^{\mathbf{4 3 4}}$ Therefore, based on the own excellent performance, the corrosion resistance of raw lacquer is further improved when adding anticorrosive preservatives. ${ }^{45,46}$

Herein, the new anticorrosion lacquer composite coatings were formed by adding dispersed waterborne graphene into raw lacquer (RL), in which graphene was modified by taken renewable and recyclable lignin tripolymer (LT) as aqueous stabilizer. LT was characterized by FT-IR, and the presence of functional groups were confirmed. Furthermore, the corrosion behavior of the lacquer composite coatings containing different mass contents of graphene were also studied on the metal substrate by polarization curve analysis and electrochemical impedance spectroscopy (EIS). The graphene/lacquer coatings showed outstanding corrosion resistance characteristics, as revealed by the obtained results.

\section{Experimental section}

\section{Materials}

Raw lacquer (RL) was collected from Hubei Province. Sodium lignosulphonate (LS), itaconic acid (IA), acrylamide (AA), ammonium persulfate, and sodium hydroxide (Sinopharm Chemical Reagent Co., Ltd) were used without further purification. trans-1,2,3-Propylene tricarboxylic acid and graphene (G) were purchased from Aladdin Industrial Corporation.
Crystalline $\mathrm{NaCl}$ (99.2\%) was used to prepare a $3.5 \mathrm{wt} \% \mathrm{NaCl}$ aqueous solution. All chemicals used were used as received.

\section{Synthesis of lignin tripolymer (LT)}

$1 \mathrm{~g}$ of LS, $0.035 \mathrm{~g}$ of ammonium persulfate, and $19.000 \mathrm{~g}$ of deionized water were added to a $250 \mathrm{~mL}$ three-necked flask and stirred at room temperature for $20 \mathrm{~min}$ to allow complete dissolution of LS. Subsequently, $4.000 \mathrm{~g}$ of trans-1,2,3-propylene tricarboxylic acid and $4.000 \mathrm{~g}$ of ammonium acrylate were added to the above-mentioned solution at $75{ }^{\circ} \mathrm{C}$ for $4.5 \mathrm{~h}$ under a nitrogen atmosphere. After cooling down to room temperature, the solution was added dropwise to $250 \mathrm{~mL}$ of isopropanol to obtain the crude product. The crude product was subsequently Soxhlet extracted for $8 \mathrm{~h}$ with an acetone solution. Finally, the resulting LT product was vacuum dried at $35^{\circ} \mathrm{C}$.

\section{Preparation of efficient waterborne graphene dispersion (LTG)}

Typically, $0.1 \mathrm{~g}$ of LT powders were added to $20 \mathrm{~mL}$ of deionized water and subsequently sonicated for $10 \mathrm{~min}$. The $\mathrm{pH}$ of the solution was adjusted to 8-9 by $\mathrm{NaOH}$ aqueous. The resulting solution was subsequently added to $0.1 \mathrm{~g}$ of graphene and sonicated in a $600 \mathrm{~W}$ sonicator for 3-4 h to obtain the LTG mixed dispersion solution.

\section{Preparation of the tinplate and copper pieces}

The metal substrates used were commercial pure tinplate and copper pieces. These pieces were polished with sandpaper to remove rust and metal oxide before use. Once grounded, the metal substrates were cleaned with distilled water, ultrasonically treated in ethanol glass containers for $10 \mathrm{~min}$, and finally dried under air.

\section{Preparation of the corrosion coatings (RL/LTG)}

The RL/LTG coatings were prepared by adding the obtained LTG dispersion to the raw lacquer at different mass fractions $(3,5$, and $10 \mathrm{wt} \%$ ) to yield graphene dosages of $0.2,0.3$, and $0.6 \mathrm{wt} \%$, respectively. Those coatings were labeled as RL/LTG-3, RL/LTG5 , RL/LTG-10. After stirring at room temperature for $0.5 \mathrm{~h}$, the components were coated on the surface of the pre-treated tinplate and copper pieces. The specimens were dried in a constant temperature and humidity chamber $\left(T=25{ }^{\circ} \mathrm{C}\right.$, relative humidity $\mathrm{RH}=85 \%$ ). A graphene-free lacquer coating (noted RL) was prepared in a similar way for comparison.

\section{Characterization experiments}

The ultraviolet-visible (UV-vis) spectra were recorded on a UV-vis spectrometer (UV-vis-2600, Shimadzu Corporation, Japan). FTIR measurements $(\mathrm{KBr})$ were conducted on an American Nicolet 5700 FT-IR spectrometer between 4000 and $400 \mathrm{~cm}^{-1}$. Thermogravimetry (TG) and derivative thermogravimetric analysis (DTG) measurements were carried out over the corrosion coatings (5-10 mg) on a DSC822e-type thermogravimetric analyzer (Mettler-Toledo) under a nitrogen atmosphere. The weight loss signal was monitored as the samples were heated at 
a rate of $10{ }^{\circ} \mathrm{C} \min ^{-1}$ up to a maximum temperature of $600{ }^{\circ} \mathrm{C}$. Scanning electron microscopy (SEM) images were obtained on a field-emission scanning electron microscope (JSM-7500) under vacuum with an accelerating voltage of $20 \mathrm{kV}$. The anticorrosion performance of all samples was tested on a CHI660E electrochemical analyzer (Shanghai, China) in a $3.5 \mathrm{wt} \%$ standard aqueous $\mathrm{NaCl}$ solution with a threeelectrode (a working electrode, a saturated calomel reference electrode, and a platinum auxiliary electrode) arrangement at $25{ }^{\circ} \mathrm{C}, 10$ points per decade, and an amplitude of 10 (rms) after checking the open circuit potential (OCP) for $5 \mathrm{~min}$. The frequency range was $10^{5}$ to $10^{-2} \mathrm{~Hz}$. When immersing the samples for a long time, it is necessary to change uninterruptedly the $\mathrm{NaCl}$ solution to reduce the interferences. A ZView software was used to fit the impedance diagram obtained.

\section{Results and discussion}

\section{Characterization of the synthesized LT polymer}

The first step modified lignin (ML) monomer was obtained by etherification of sodium lignosulfonate and trans-1,2,3propylene tricarboxylic acid. And then LT was further polymerized from ML monomer and ammonium acrylate with trans-1,2,3-propylene tricarboxylic acid. The synthetic routes to LT are shown in Scheme 1.

FT-IR measurements were carried out to investigate and confirm the structures of the LS and LT polymer, and the spectra are shown in Fig. 1(a). The spectrum of the LS monomer showed the presence of a stretching vibration peak at $3440 \mathrm{~cm}^{-1}$ which was ascribed to the phenolic hydroxyl group. This peak was replaced with a band of $\mathrm{O}=\mathrm{C}-\mathrm{NH}$ in the spectra of the $\mathrm{LT}$ polymer. Moreover, new absorption bands ascribed to $\mathrm{O}=\mathrm{C}-\mathrm{NH}$ and $\mathrm{O}=\mathrm{C}-\mathrm{O}$ groups were observed at $3230-3180$ and 1725$1720 \mathrm{~cm}^{-1}$, respectively. The absorption peak at $1455 \mathrm{~cm}^{-1}$ was associated to $\mathrm{O}=\mathrm{C}-\mathrm{NH}$ and $\mathrm{N}-\mathrm{H}$ extending vibrations. Besides, the spectra of LT and LS were slightly different, and these results demonstrated that LT composite material was synthesized.

As shown in Fig. 1(b), UV spectroscopy analysis of the LTG dispersion was carried out. LT showed absorption at $274 \mathrm{~nm}$, and this signal was assigned to the $n-\pi *$ electron transition. However, these peak was detected at $240 \mathrm{~nm}$ for the LTG dispersion (i.e., blue-shifted by $34 \mathrm{~nm}$ with regard to LT). These result proved the existence of a $\pi-\pi$ interaction between the LT polymer and the graphene material. ${ }^{47,48}$
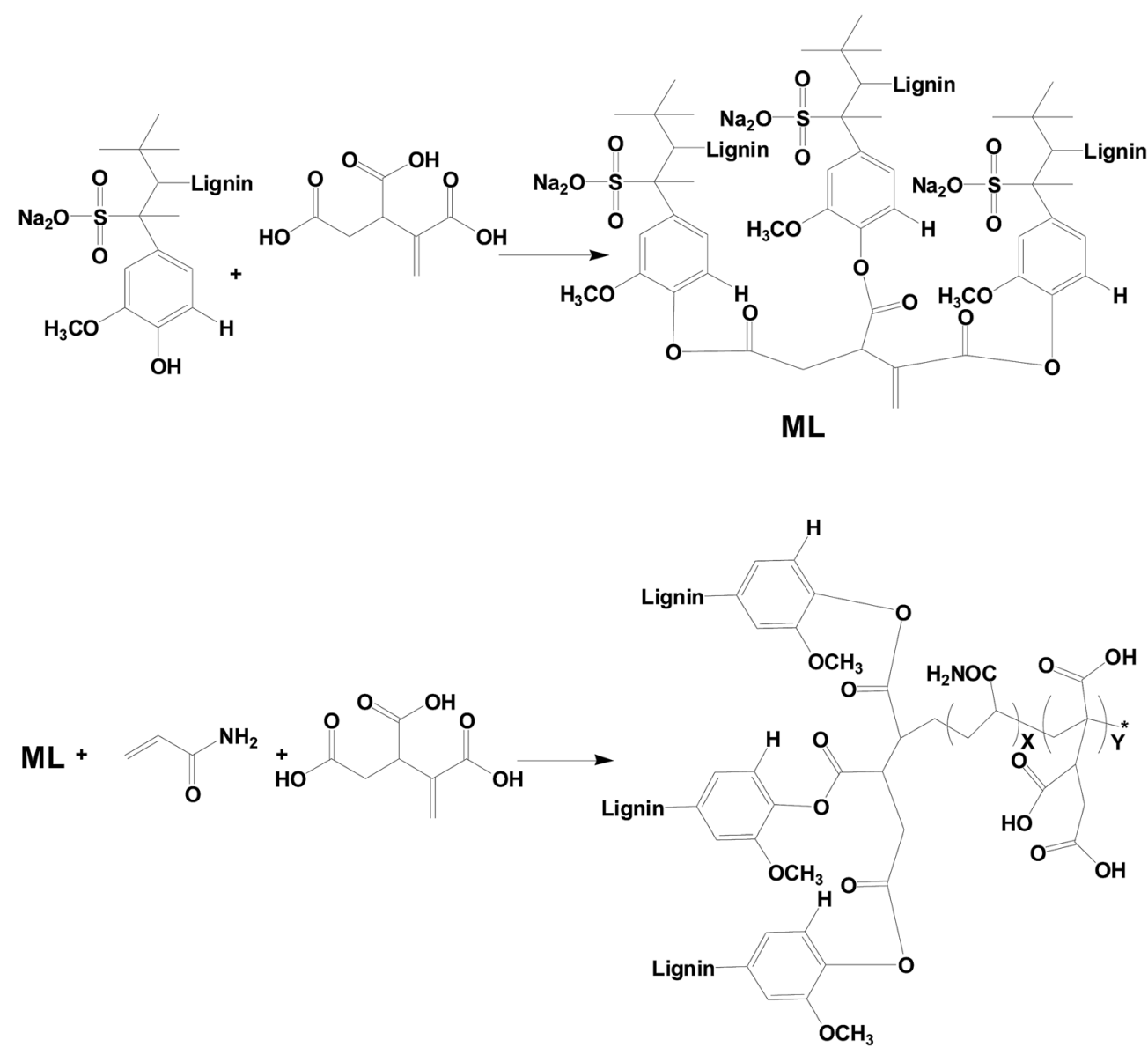

LT

Scheme 1 Synthesis of LT polymer. 

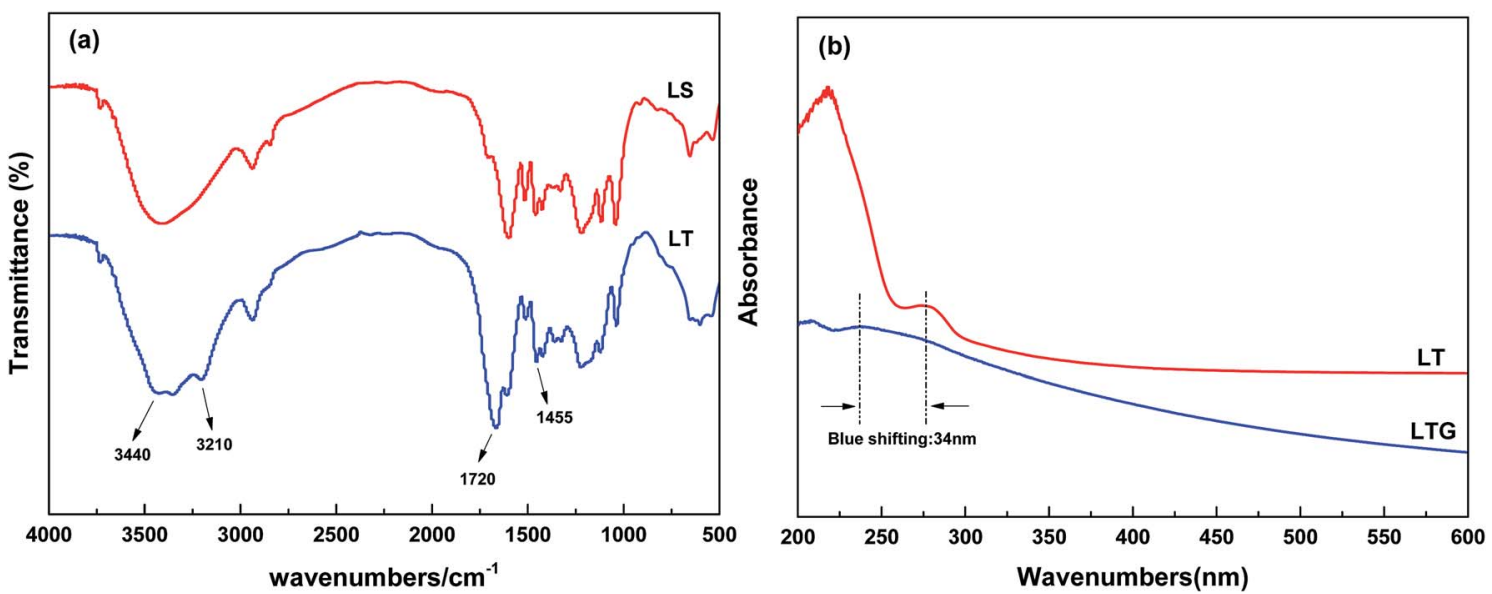

Fig. 1 (a) FT-IR spectra of LS and LT, (b) UV spectroscopy of LT aqueous solution and waterborne graphene (LTG).

\section{SEM analysis of graphene, waterborne graphene and different coatings}

To analyze the internal morphologies of LTG dispersion, their cross-sections were examined by SEM imaging. The morphologies of graphene as well as the fracture surface images of LTG were shown in Fig. 2. The images revealed the large specific area of graphene in Fig. 2(a). Additionally, as shown in Fig. 2(b), the graphene material was well dispersed and no aggregations were observed. These results seem to indicate that the excellent protection properties of these coatings can be mainly ascribed to the formation of a rough surface comprised of highly dispersed graphene nanoparticles. As shown in Fig. 2(c), the RL/ LTG-5 film containing $0.3 \mathrm{wt} \%$ graphene provided the coating with a relatively rough surface compared with RL film in Fig. 2(d). This rough surface minimized the direct contact between the aggressive species and the coating itself.

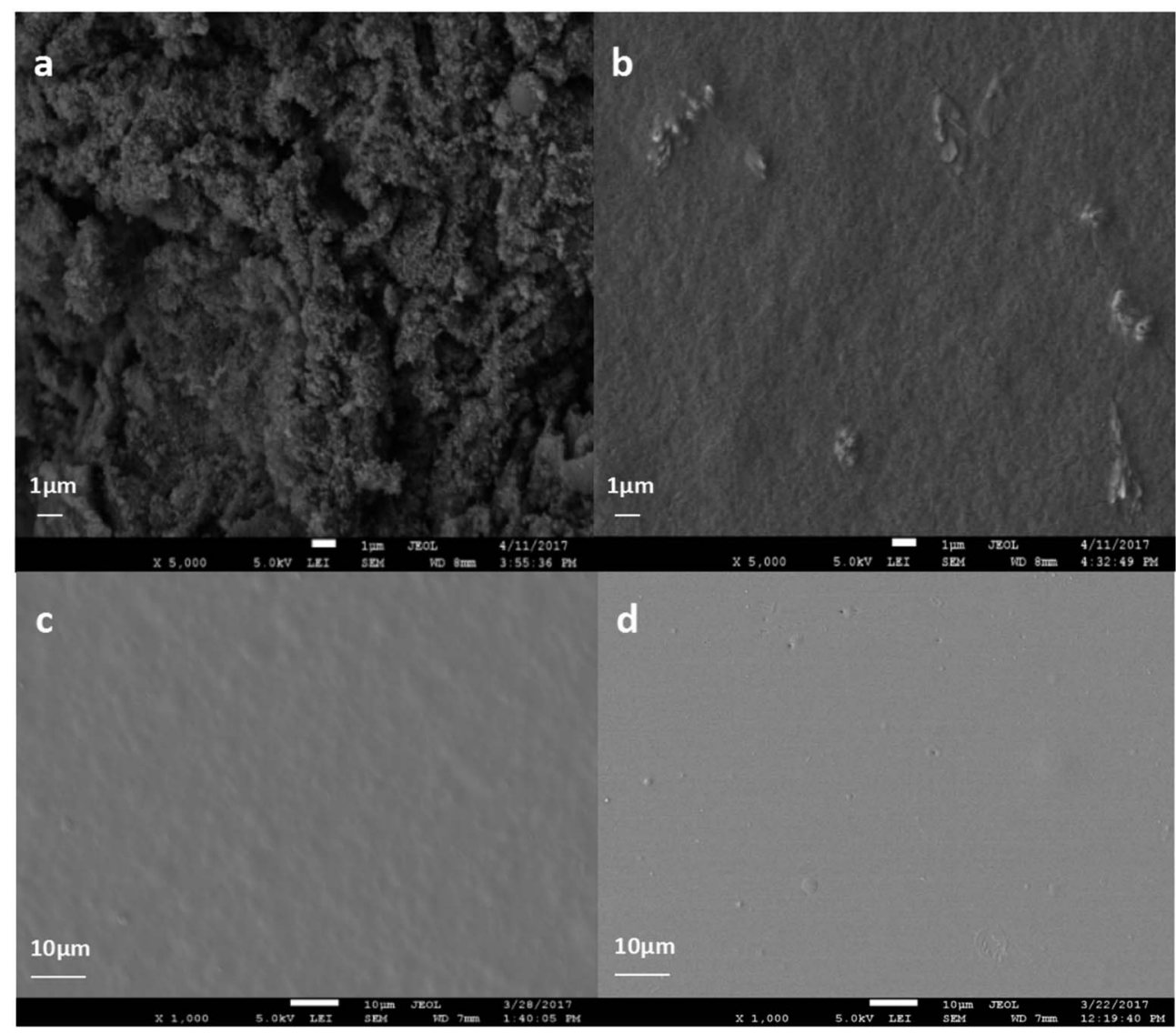

Fig. 2 SEM for (a) pristine graphene, (b) LTG, (c) RL/LTG-5 film and (d) RL film. 


\section{Characteristics of waterborne graphene dispersion}

Agglomeration of graphene seriously limits its practical applications in industrial production. ${ }^{\mathbf{1 2}}$ This important barrier is expected to be overcome by developing synthesis approaches for dispersed graphene. After dispersing waterborne graphene by LT aqueous, the LTG dispersion was high concentration $(5 \mathrm{mg}$ $\mathrm{mL}^{-1}$ ) with excellent stability, and no obvious precipitation were observed after $60 \mathrm{~d}$ of storage as shown in Fig. 3(A). The graphene aqueous dispersion lacking LT stabilizers presented agglomerates and precipitates after $5 \mathrm{~d}$ of storage, as shown in Fig. 3(B). Thus, LT acts as an efficient graphene aqueous dispersant.

\section{TG analysis of $R L$ and RL/LTG coatings}

The RL/LTG-5 and RL coatings showed in Fig. 4 possessed good thermal stability. Because of thermodynamical stability of nanometer-sized particle graphene, RL/LTG-5 film slightly stabilized to RL film. RL/LTG-5 film can be seen that the degrades in a two-stage major weight-loss process: the first onset weight loss, observed at $273.8{ }^{\circ} \mathrm{C}$ and continued with around $20 \%$ total weight loss at $376.0^{\circ} \mathrm{C}$, is associated with the degradation at not completely cross-linking urushiol oligomers and other constituents, such as glycoproteins and polysaccharide exited through hydrogen bonding. The second and further succeeding onset higher temperature weight losses in the range of $408.5-472.3{ }^{\circ} \mathrm{C}$ (weight loss was about $49.8 \%$ ) was ascribed to the decomposition of polymer. RL/LTG-5 film showed higher thermal char yield (21.6\%) (Table 1).

\section{Electrochemical analysis of the RL/LTG and RL films}

The RL/LTG and RL films were investigated by means of a series of electrochemical measurements. Open-circuit potential (OCP) measurements were first performed when the samples immersed in the $3.5 \mathrm{wt} \%$ aqueous $\mathrm{NaCl}$ solution for $0.5 \mathrm{~h}$ to ensure steady-state conditions. Immediately after this treatment, the potential was varied from OCP conditions, and the logarithm of the resulting current was plotted against the

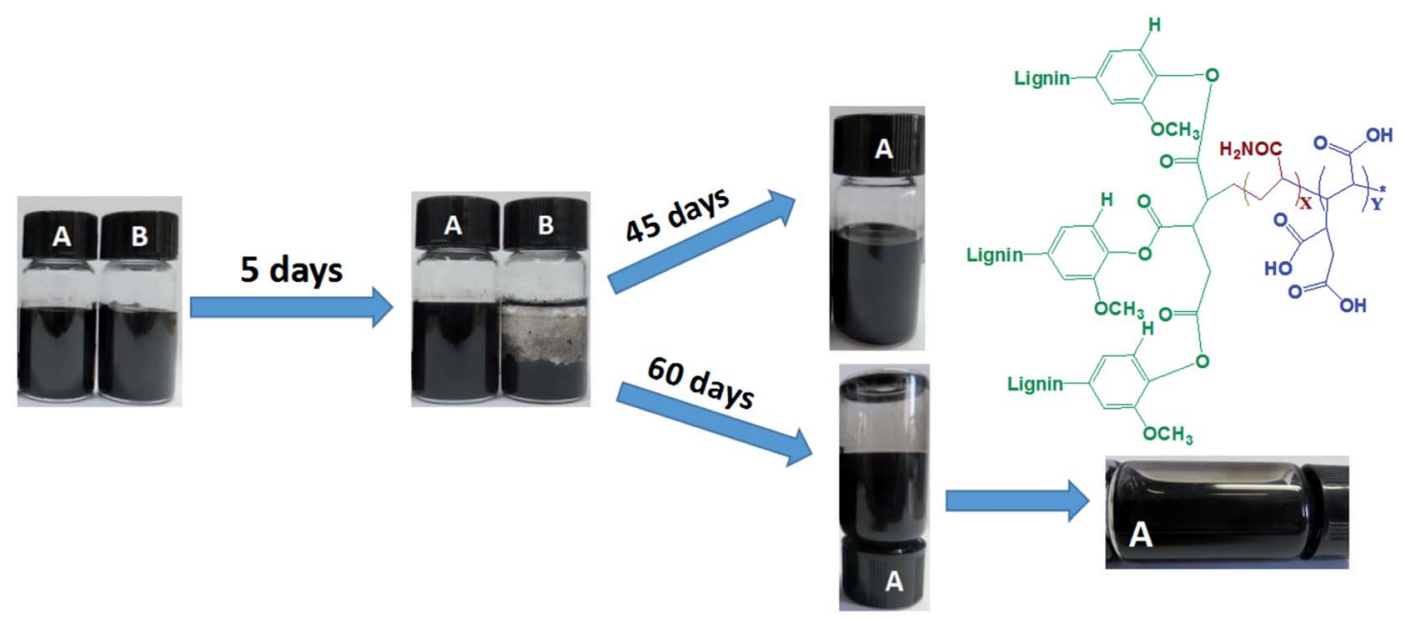

Fig. 3 Digital images of (A) LTG and (B) water dispersion of graphene.

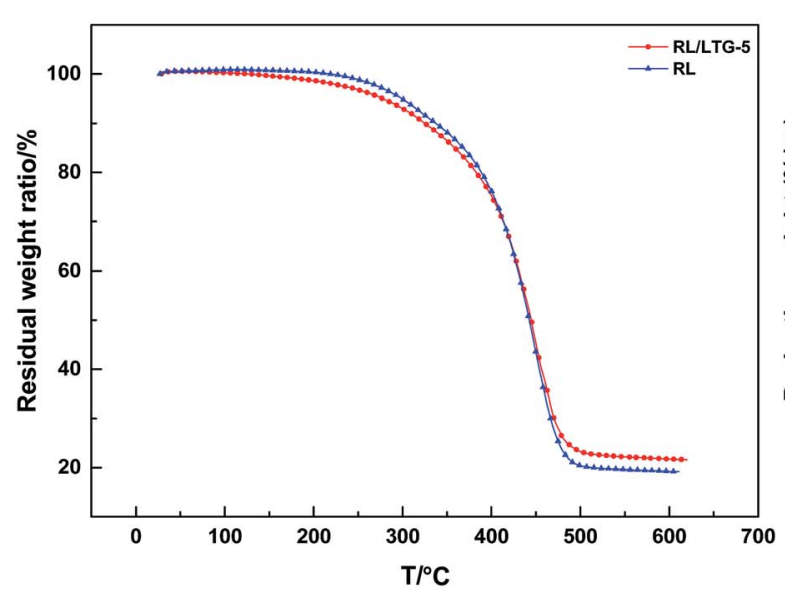

(a)

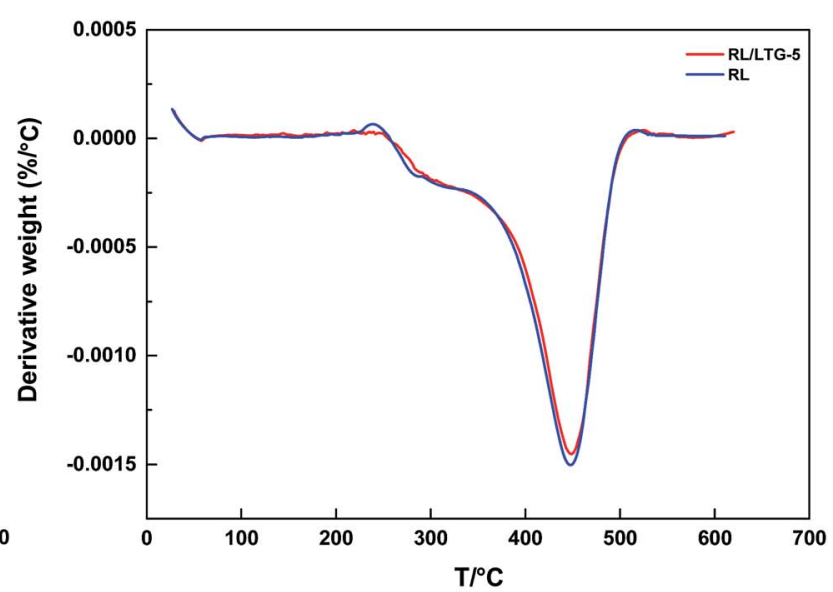

(b)

Fig. 4 (a) The thermogravimetric analysis RL/LTG-5 and RL coatings and (b) weight loss derivative curves. 
Table 1 Thermal decomposition parameters of RL/LTG-5 and RL films

\begin{tabular}{lllll}
\hline Sample & $T^{a}\left({ }^{\circ} \mathrm{C}\right)$ & $T^{b}\left({ }^{\circ} \mathrm{C}\right)$ & $T^{c}\left({ }^{\circ} \mathrm{C}\right)$ & Char yield $/ \%$ \\
\hline RL/LTG-5 & 273.8 & 445.2 & 447.1 & 21.6 \\
RL & 262.2 & 441.5 & 451.2 & 19.2
\end{tabular}

${ }^{a}$ Onset weight loss. ${ }^{b}$ Weight loss to $50 \% .{ }^{c}$ Weight loss to maximum.

applied potential to quantify the anti-corrosion performance of the samples. The corrosion currents $\left(I_{\text {corr }}\right)$ and potentials $\left(E_{\text {corr }}\right)$ were subsequently determined by numerically fitting the resulting plots, (i.e., Tafel polarization curves), to the ButlerVolmer equation. ${ }^{49-51}$ This procedure represents a significant improvement over the traditional Tafel extrapolation method. ${ }^{52-54}$ During the analysis of the polarization curve, $I_{\text {corr }}$ and $E_{\text {corr }}$ were observed to change with the immersion time of the coating while increasing the anode potential by the dynamic potential analysis method.

Generally, a higher $E_{\text {corr }}$ and a lower $I_{\text {corr }}$ indicate better corrosion protection. As showed in Fig. 5, the bare steel and RL film, after $0.5 \mathrm{~h}$ of immersion, had the following: $I_{\text {corr }}$ of $8.310 \times$ $10^{-6}$ and $4.200 \times 10^{-9} \mathrm{~A} \mathrm{~cm}^{-2}$, respectively, and $E_{\text {corr }}$ of -0.5510 and $-0.4430 \mathrm{~V}$, respectively. While, LTG-coatings were

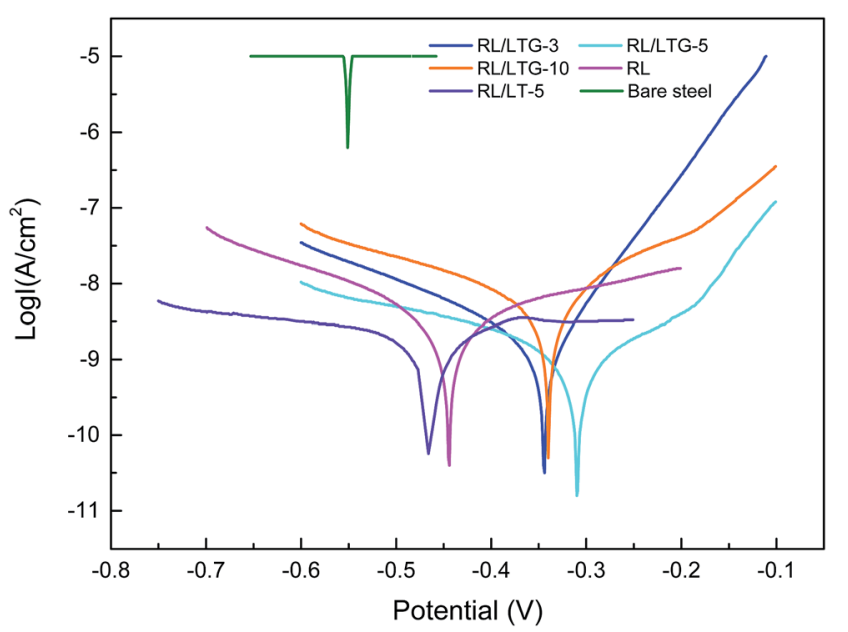

Fig. 5 Tafel curves of different coatings and bare steel in $3.5 \mathrm{wt} \% \mathrm{NaCl}$ solution. evidenced the positive results. The RL/LTG-3, RL/LTG-5, RL/ LTG-10 coatings showed $I_{\text {corr }}$ of $1.209 \times 10^{-9}, 4.153 \times 10^{-10}$, $1.178 \times 10^{-9} \mathrm{~A} \mathrm{~cm}^{-2}$, respectively, and $E_{\text {corr }}$ of -0.3443 , $-0.3099,-0.3402 \mathrm{~V}$. When only $5 \mathrm{wt} \%$ LT aqueous solution was adding into the RL to form RL/LT- 5 film, the film had a negative result with $I_{\text {corr }}$ of $3.582 \times 10^{-9} \mathrm{~A} \mathrm{~cm}^{-2}$ and $E_{\text {corr }}$ of $-0.4623 \mathrm{~V}$. Therefore, comparison of these values apparently implies that the RL/LTG coatings demonstrated some anti-corrosion property against exposure to harsh chemical conditions, thus preventing oxidation and corrosion. ${ }^{55,56}$ For a better understanding of such comparison, the numerical values involved are tabulated in Table 2 . Note that the polarization resistance $\left(R_{\mathrm{p}}\right)$ values were calculated from the Tafel plots, according to the StearnGeary equation (eqn (1))..$^{57-59}$ And the corrosion rate (CR) and the protection efficiency (PE) were calculated using the following formula eqn (2) and (3).

$$
R_{\mathrm{p}}=\frac{b_{\mathrm{a}} b_{\mathrm{c}}}{2.303\left(b_{\mathrm{a}}+b_{\mathrm{c}}\right) I_{\text {corr }}}
$$

where $I_{\text {corr }}$ is determined by the intersection of the linear portions of the anodic and cathodic curves, and $b_{\mathrm{a}}$ and $b_{\mathrm{c}}$ are the anodic and cathodic slopes (DE/D log $I)$, respectively. ${ }^{60}$

The CR was calculated as follows: ${ }^{45}$

$$
\mathrm{CR}(\mathrm{mm} \text { per year })=\frac{I_{\text {corr }}\left(\mathrm{A} \mathrm{cm}^{-2}\right) \cdot M(\mathrm{~g})}{D\left(\mathrm{~g} \mathrm{~cm}^{-3}\right) \cdot V}
$$

where $M$ is the molecular weight, $V$ is the valence, 3270 is a constant, and $D$ is the density. $I_{\text {corr,bare }}$ and $I_{\text {corr,coated }}$ stand for the corrosion current density for the lacquer and the graphenedoped lacquer materials, respectively.

$$
\mathrm{PE}=\frac{I_{\text {corr,bare }}-I_{\text {corr,coated }}}{I_{\text {corr,bare }}} \times 100 \%
$$

Generally, a higher $R_{\mathrm{p}}$ and a lower CR reflect better corrosion protection. Thus, the bare and RL showed $R_{\mathrm{p}}$ value of $1.456 \times$ $10^{5}$ and $7.975 \times 10^{7} \Omega$, while RL/LTG-3, RL/LTG-5, RL/LTG-10 coatings owned the positive $R_{\mathrm{p}}$ of $6.045 \times 10^{8}, 1.895 \times 10^{9}$ and $6.819 \times 10^{8} \Omega$, respectively. Besides, the CR value of RL/LTG coatings were lower than $1.270 \times 10^{-5} \mathrm{~mm}$ per year while the bare steel and RL had CR of $8.726 \times 10^{-2}$ and $4.411 \times 10^{-5} \mathrm{~mm}$ per year. Additionally, the PE of RL and RL/LTG coatings were

\begin{tabular}{|c|c|c|c|c|c|c|}
\hline \multirow[b]{2}{*}{ Sample } & \multicolumn{2}{|c|}{$\begin{array}{l}\text { Electrochemical corrosion } \\
\text { measurements }\end{array}$} & \multirow[b]{2}{*}{$R_{\mathrm{p}}(\Omega)$} & \multirow[b]{2}{*}{ CR (mm per year) } & \multirow{2}{*}{\multicolumn{2}{|c|}{$\mathrm{PE} / \%$}} \\
\hline & $E_{0} / \mathrm{V}$ & $I_{0} /\left(\mathrm{A} \mathrm{cm}^{-2}\right)$ & & & & \\
\hline Bare steel & -0.5510 & $8.310 \times 10^{-6}$ & $1.456 \times 10^{5}$ & $8.726 \times 10^{-2}$ & $0^{a}$ & ${ }_{-}^{a}$ \\
\hline $\mathrm{RL}$ & -0.4430 & $4.200 \times 10^{-9}$ & $7.975 \times 10^{7}$ & $4.411 \times 10^{-5}$ & 99.94 & $\overline{0}$ \\
\hline RL/LTG-3 & -0.3443 & $1.209 \times 10^{-9}$ & $6.045 \times 10^{8}$ & $1.270 \times 10^{-5}$ & 99.98 & 71.21 \\
\hline RL/LTG-5 & -0.3099 & $4.153 \times 10^{-10}$ & $1.895 \times 10^{9}$ & $4.361 \times 10^{-6}$ & 99.99 & 90.11 \\
\hline RL/LTG-10 & -0.3402 & $1.178 \times 10^{-9}$ & $6.819 \times 10^{8}$ & $1.237 \times 10^{-5}$ & 99.98 & 71.95 \\
\hline RL/LT-5 & -0.4623 & $3.582 \times 10^{-9}$ & $5.124 \times 10^{7}$ & $3.762 \times 10^{-5}$ & 99.94 & 14.71 \\
\hline
\end{tabular}
$99.9 \%$, which enhanced the anti-corrosion property. On the

Table 2 Relevant chemical parameters different coatings from the Tafel curve

${ }^{a} 0$ - based on this sample; _ - exclude this sample. 
contrary, the relevant value of RL/LT-5 film were more terrible than RL/LTG coatings, especially PE of $14.71 \%$. Compared to the RL/LTG coatings, LT didn't obviously improve coatings anticorrosion property. Only the RL/LTG-5 film managed to maintain a highest $E_{\text {corr }}$ value and a very lowest $I_{\text {corr }}$ that corresponded to a very high protection efficiency of $90.11 \%$ compared to RL film and bare steel.

EIS allows effective evaluation of the dielectric properties of a medium. ${ }^{61}$ Fig. 6 shows the partial EIS spectra of the RL/LTG coatings immersed in a $3.5 \mathrm{wt} \% \mathrm{NaCl}$ aqueous solution for varying times $(0.5,24,48,72,96$ and $120 \mathrm{~h})$. The size of the curve in the spectrum allows determining the chemical resistance of the coating. ${ }^{62}$ Initial stage of immersion at 0.5 and $24 \mathrm{~h}, \mathrm{RL}$ and RL/LTG coatings had capacity reactance arc in low-frequency area, and the film was an effective barrier to corrosion medium. As the immersing time increased at 72 to $120 \mathrm{~h}$, the high-frequency area $\left(2 \times 10^{4} \mathrm{ohms}\right)$ of RL, RL/LTG-3 and RL/ LTG-10 coatings began to show capacity reactance arc, and the protective coating effect of films gradually failed. ${ }^{63-65}$ RL/LTG-5 film did not appear to be resistant to arcing in the high frequency area after $120 \mathrm{~h}$ of soaking, thereby demonstrating good protection characteristics as a metal barrier. This excellent
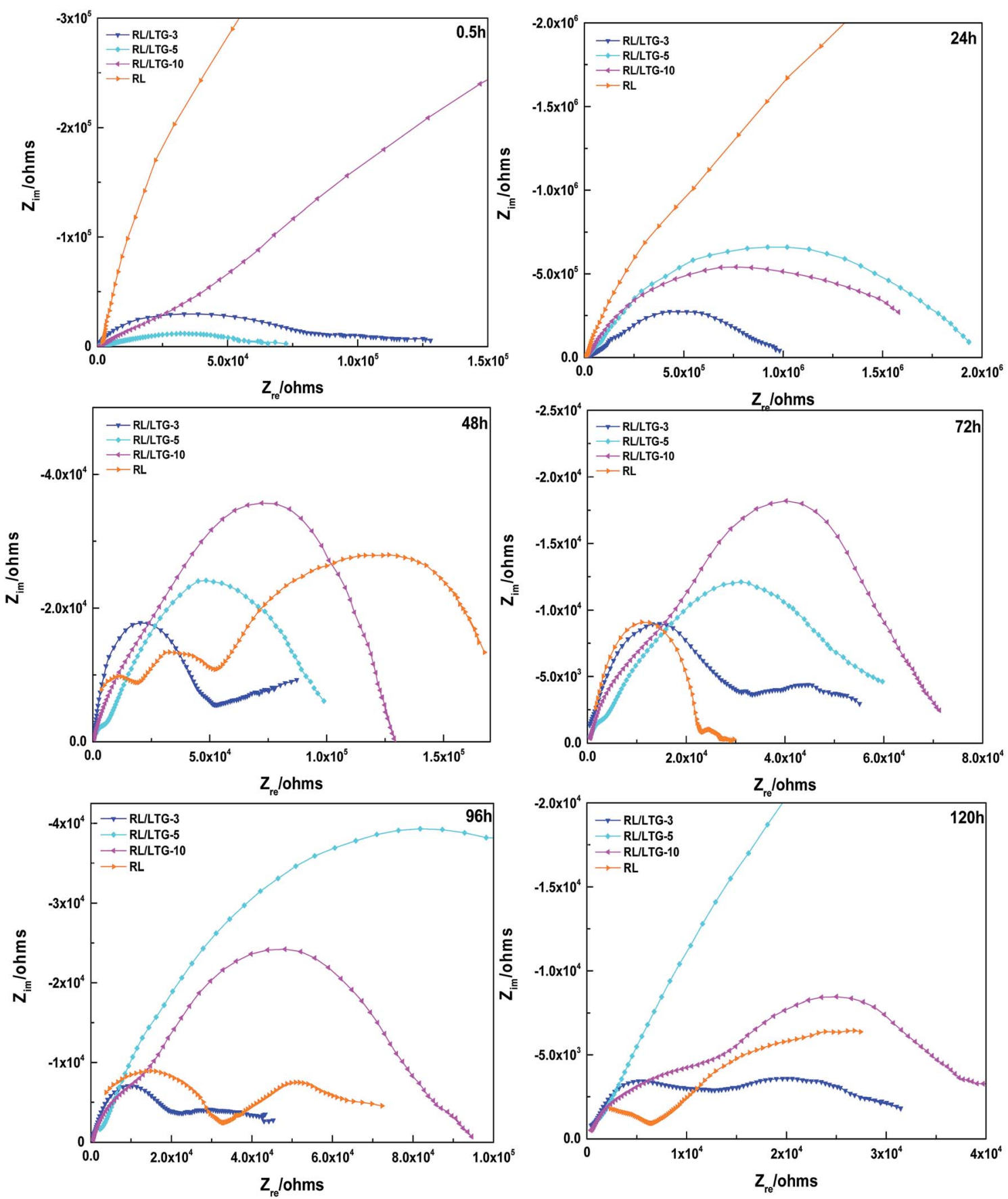

Fig. 6 Nyquist plots for different films measured in $3.5 \mathrm{wt} \% \mathrm{NaCl}$ solution after different times. 
protection property is highly attributable to the formation of a rough surface brought about by the presence of the graphene nanoparticles on the outer layer of the coating. As depicted in Fig. 2(c), mainly, the presence of trapped air in the nanoscale trenches of the rough surface is responsible for minimizing the direct contact between the aggressive species and the coating itself. Thus, this indicates that the dissolution of the bare steel
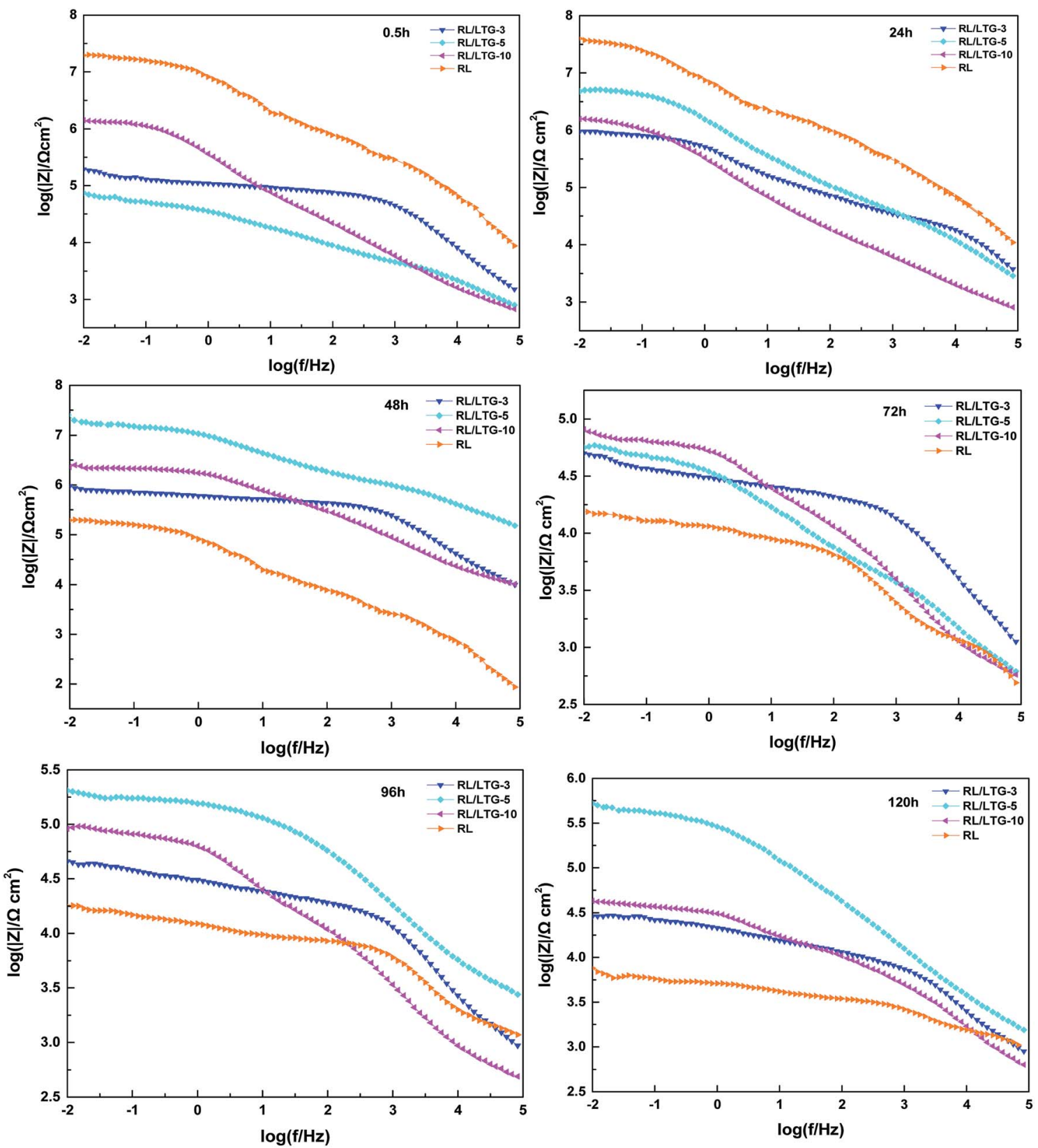

Fig. 7 Bode plots results for different films measured in 3.5 wt\% $\mathrm{NaCl}$ solution.

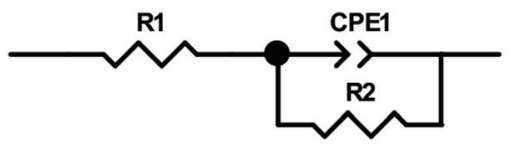

(a)

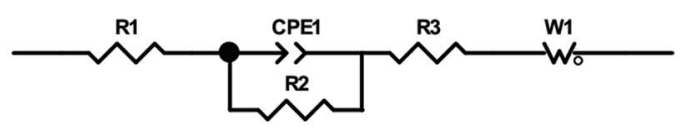

(b)

Fig. 8 Equivalent electrical circuits and physical models for (a) RL, (b) RL/LTG coatings during a prolonged exposure time in 3.5 wt\% NaCl solution. 
and the aggressive attack of chlorides are strongly restrained by the RL/LTG-5 coating surface.

Generally, the enhanced corrosion protective performance were further evidenced from the Bode plots (Fig. 7), where modified lacquer with graphene show a higher impedance value at low frequency, which are associated with ionic transport through the film. This is a clear indication about that the RL/ LTG-5 coating, with an added graphene mass fraction of $0.3 \mathrm{wt} \%$, performed the excellent protection against corrosion when increasing the immersing time. The fitting of the experimental data obtained from the EIS parameters was accomplished by using the equivalent electrical circuits shown in Fig. 8(a) and (b). The equivalent circuits consisted of the electrolyte resistance $\left(R_{\mathrm{S}}\right)$, the constant phase elements (CPE), and the Warburg element $\left(W_{\mathrm{o}}\right)$. By this definition, we can calculate $R_{\mathrm{p}}$ with the following equations for the corresponding models:

Model 1:

$$
\frac{1}{R_{\mathrm{p}}}=\frac{1}{R_{1}+R_{2}}
$$

Model 2:

$$
\frac{1}{R_{\mathrm{p}}}=\frac{1}{R_{1}+R_{2}+R_{3}+R_{\mathrm{w} 1}}
$$

\section{Study of the preservative mechanism of the graphene/raw lacquer coatings}

Corrosive mediums (e.g., $\mathrm{H}_{2} \mathrm{O}, \mathrm{O}_{2}$, and $\mathrm{Cl}^{-}$) are known to easily penetrate coatings through tiny surface cracks. ${ }^{66}$ Thus, corrosion of metal substrates can be effectively avoided if corrosive mediums are prevented from accessing the metal surface (Fig. 9 and 10).

$$
\begin{aligned}
& \mathrm{Fe} \longrightarrow \mathrm{Fe}^{2+}+2 \mathrm{e}^{-} \\
& \mathrm{Fe}^{2+} \longrightarrow \mathrm{Fe}^{3+}+1 \mathrm{e}^{-} \\
& \mathrm{O}_{2}(\mathrm{~g})+\mathrm{H}_{2} \mathrm{O}+4 \mathrm{e}^{-} \longrightarrow 4 \mathrm{OH}^{-} \\
& \mathrm{Fe}^{3+}+\mathrm{LT} \longrightarrow \mathrm{Fe}^{3+}[\mathrm{LT}]
\end{aligned}
$$

Fig. 9 Mechanism research of graphene/lacquer anti-corrosion coatings.
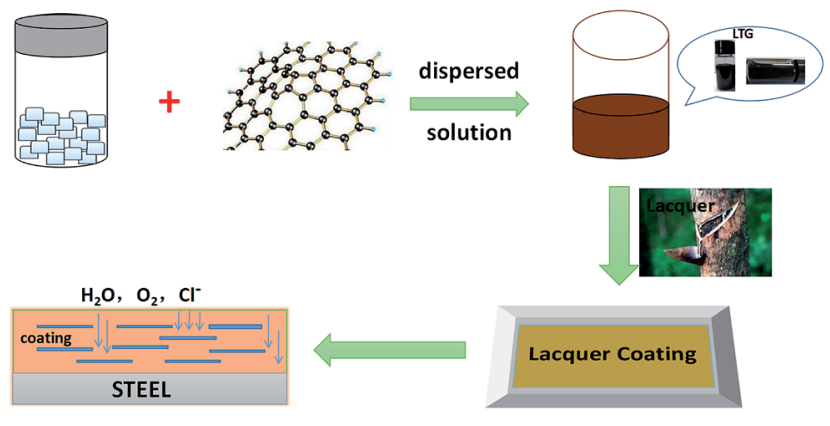

Fig. 10 Schematic diagram of graphene/lacquer anti-corrosive coatings.
The corrosion resistance of graphene-doped lacquer coatings (RL/LTG) were significantly improved, mainly in the following aspects. Firstly, the higher cross-linking density raw lacquer film was responsible for the good shielding effect of the base. Secondly, due to graphene low permeability to reduce corrosion mediums, oxygen and $\mathrm{H}_{2} \mathrm{O}$ gases, the galvanic cell between graphene and metal substrate promotes extensive anticorrosion. Thirdly, because of special flake structure, graphene can increase the tortuous diffusion pathways avoiding corrosion mediums directly accessing the substrate surface, leading a good anti-corrosion property. ${ }^{67}$ When graphene highly dispersed in LT aqueous solution in virtue of van der Waals forces, the good anti-corrosion properties of graphene can be fully used.

The electrostatic interaction of $\mathrm{N}^{+}$species in the LT polymers can help adsorbing the coatings on the metal surface, thereby avoiding corrosive ion and atoms such as $\mathrm{H}^{+}, \mathrm{O}_{2}$, and $\mathrm{Cl}^{-}$to contact the metal substrate. Moreover, LT polymer, containing a higher number of $-\mathrm{NH},-\mathrm{C}=\mathrm{O},-\mathrm{OH},-\mathrm{CONH}$, and other groups have an electron pair prone to form a conjugate, and the conjugation efficiency and chemical bond strength between atoms were higher. Furthermore, the LT structures provided a barrier effect for forming complexes with $\mathrm{Fe}^{3+}$ ions on the metal surface. Above all, it can be considered in anti-corrosion coating applications maintaining the LTG solution are desirable.

\section{Conclusions}

The waterborne graphene dispersion (LTG) was modified by taking lignin tripolymer (LT) as a aqueous stabilizer with excellent effect. After $60 \mathrm{~d}$, LTG dispersant at high concentration (5 $\mathrm{mg} \mathrm{mL} \mathrm{mL}^{-1}$ ) remained uniformly dispersed without any precipitation. In addition, when LTG dispersant was added to raw lacquer (RL), the new natural renewable composite anticorrosion coatings were formed and showed superior corrosion resistances. Particularly RL/LTG-5 film had the lowest value of $I_{\text {corr }}\left(4.153 \times 10^{-10} \mathrm{~A} \mathrm{~cm}^{-2}\right)$, the lowest CR $\left(4.361 \times 10^{-6} \mathrm{~mm}\right.$ per year), the highest $R_{\mathrm{p}}\left(1.895 \times 10^{9} \Omega\right)$ and $\mathrm{PE}(99.99 \%$, $90.11 \%)$. Most importantly, excellent anti-corrosion graphene/ lacquer composite coatings, a kind of free volatile organic compounds (VOCs), were environmentally friendly product and people-friendly material achieved by eco-friendly process of fabrication. Herein, the green RL/LTG coatings are promising in the applications to the field of corrosion protection.

\section{Conflicts of interest}

There are no conflicts to declare.

\section{Acknowledgements}

This project is supported by Fujian Province Science and Technology Project: School-enterprise cooperation in science and engineering (2016 Y4001), and the Special Projects on Development of Marine Hightech Industry in Fujian Province [No. 25(2015)]. 


\section{References}

1 F. Renner, A. Stierle, H. Dosch, D. Kolb, T.-L. Lee and J. Zegenhagen, Nature, 2006, 439, 707-710.

2 O. u. Rahman and S. Ahmad, RSC Adv., 2014, 4, 14936-14947.

3 J. T. Robinson, F. K. Perkins, E. S. Snow, Z. Wei and P. E. Sheehan, Nano Lett., 2008, 8, 3137-3140.

4 L. Kyhl, S. F. Nielsen, A. G. Čabo, A. Cassidy, J. A. Miwa and L. Hornekær, Faraday Discuss., 2015, 180, 495-509.

5 L. Xu, M. Jia, Y. Li, S. Zhang and X. Jin, RSC Adv., 2017, 7, 31342-31351.

6 S. Han, W. Zhai, G. Chen and X. Wang, RSC Adv., 2014, 4, 29281-29285.

7 G. Chen, W. Xu and D. Zhu, J. Mater. Chem. C, 2017, 5, 43504360.

8 D. Tan, J. Zhao, C. Gao, H. Wang, G. Chen and D. Shi, ACS Appl. Mater. Interfaces, 2017, 9, 21820-21828.

9 P. He, J. Sun, S. Tian, S. Yang, S. Ding, G. Ding, X. Xie and M. Jiang, Chem. Mater., 2014, 27, 218-226.

10 C. Zhang, S. Huang, W. W. Tjiu, W. Fan and T. Liu, J. Mater. Chem., 2012, 22, 2427-2434.

11 J. Song, R. Guo, J. Liu and B. Wang, Appl. Chem. Ind., 2015, 44, 559-662.

12 L. Gu, S. Liu, H. Zhao and H. Yu, ACS Appl. Mater. Interfaces, 2015, 7, 17641-17648.

13 P. He, J. Sun, S. Tian, S. Yang, S. Ding, G. Ding, X. Xie and M. Jiang, Chem. Mater., 2014, 27, 218-226.

14 M. A. Meier, J. O. Metzger and U. S. Schubert, Chem. Soc. Rev., 2007, 36, 1788-1802.

15 E. Ebenso, N. Eddy and A. Odiongenyi, Afr. J. Pure Appl. Chem., 2008, 2, 107-115.

16 F. S. Chakar and A. J. Ragauskas, Ind. Crops Prod., 2004, 20, 131-141.

17 Y.-L. Chung, J. V. Olsson, R. J. Li, C. W. Frank, R. M. Waymouth, S. L. Billington and E. S. Sattely, ACS Sustainable Chem. Eng., 2013, 1, 1231-1238.

18 Y. Deng, X. Feng, M. Zhou, Y. Qian, H. Yu and X. Qiu, Biomacromolecules, 2011, 12, 1116-1125.

19 F. S. Chakar and A. J. Ragauskas, Ind. Crops Prod., 2004, 20, 131-141.

20 G. Leary and D. Sawtell, Holzforschung, 1984, 38, 53-54.

21 Y.-Z. Lai and X.-P. Guo, Holzforschung, 1992, 46, 311-314.

22 P. B. Raja and M. G. Sethuraman, Mater. Lett., 2008, 62, 113116.

23 H. Chung and N. R. Washburn, ACS Appl. Mater. Interfaces, 2012, 4, 2840-2846.

24 W. Liu, R. Zhou, H. L. S. Goh, S. Huang and X. Lu, ACS Appl. Mater. Interfaces, 2014, 6, 5810-5817.

25 M. R. Tchoquessi Diodjo, L. Belec, E. Aragon, Y. Joliff, L. Lanarde and F. o. X. Perrin, ACS Appl. Mater. Interfaces, 2013, 5, 6751-6761.

26 J. Ding, S. Shi and H. Yu, International Journal of Advanced Engineering Research and Science, 2016, 3, 101-112.

27 S. Pathan and S. Ahmad, ACS Appl. Mater. Interfaces, 2013, 1, 1246-1257.

28 J. Xia, Y. Xu, J. Lin and B. Hu, Prog. Org. Coat., 2008, 61, 7-10.
29 J. Xia, J. Lin, Y. Xu and Q. Chen, ACS Appl. Mater. Interfaces, 2010, 3, 482-489.

30 J. Agbenyega, M. Claybourn and G. Ellis, Spectrochim. Acta, Part A, 1991, 47, 1375-1388.

31 N. Niimura, Int. J. Mass Spectrom., 2009, 284, 93-97.

32 J. Yang, J. Deng, Q. Zhang, Q. Shen, D. Li and Z. Xiao, Prog. Org. Coat., 2015, 78, 176-182.

33 R. Lu, T. Yoshida and T. Miyakoshi, Polym. Rev., 2013, 53, 153-191.

34 X. Li, X. Wu, Y. Zhao, Q. Wen, Z. Xie, Y. Yuan, T. Tong, X. Shen and H. Tong, Anal. Methods, 2016, 8, 6529-6536.

35 B. Hu and W. Chen, Acta Polym. Sin., 1996, 3, 278-283.

36 B. Hu, W. Chen and J. Lin, Chin. J. Polym. Sci., 1993, 11, 198203.

37 Y. Xu, B. Hu and J. Lin, Acta Polym. Sin., 2000, 3, 257-261.

38 B. Hu, J. Lin, Z. Dong and W. Chen, J. Chin. Lacq., 1995, 14, 5-11.

39 J. Lin, B. Hu, W. Chen and J. Gan, Polym. Mater. Sci. Eng., 1991, 5, 34-37.

40 B. Hu and J. Lin, J. Chin. Lacq., 1996, 15, 1-7.

41 J. Xia, Y. Xu, B. Hu and J. Lin, Prog. Org. Coat., 2009, 65, 510513.

42 J. Lin, J. Chin. Lacq., 1992, 11, 23-25.

43 B. Hu, W. Chen and J. Lin, Sci. Found. China, 1995, 13, 78-79.

44 B. Hu, W. Chen, J. Lin, F. Zhao and J. Gan, Acta Oceanol. Sin., 1990, 9, 97-107.

45 S. Pathan and S. Ahmad, ACS Sustainable Chem. Eng., 2016, 4, 3062-3075.

46 P. Alagi, R. Ghorpade, Y. J. Choi, U. Patil, I. Kim, J. H. Baik and S. C. Hong, ACS Sustainable Chem. Eng., 2017, 5, 3871-3881.

47 S. Liu, L. Gu, H. Zhao, J. Chen and H. Yu, J. Mater. Sci. Technol., 2016, 32, 425-431.

48 L. Gu, S. Liu, H. Zhao and H. Yu, ACS Appl. Mater. Interfaces, 2015, 7, 17641-17648.

49 E. B. Caldona, A. C. C. De Leon, P. G. Thomas, D. F. Naylor III, B. B. Pajarito and R. C. Advincula, Ind. Eng. Chem. Res., 2017, 56, 1485-1497.

50 M. Bhardwaj and R. Balasubramaniam, Int. J. Hydrogen Energy, 2008, 33, 248-251.

51 A. C. C. de Leon, R. B. Pernites and R. C. Advincula, ACS Appl. Mater. Interfaces, 2012, 4, 3169-3176.

52 M. Stern, J. Electrochem. Soc., 1955, 102, 609-616.

53 M. Mo, W. Zhao, Z. Chen, Q. Yu, Z. Zeng, X. Wu and Q. Xue, RSC Adv., 2015, 5, 56486-56497.

54 T.-C. Huang, Y.-A. Su, T.-C. Yeh, H.-Y. Huang, C.-P. Wu, K.-Y. Huang, Y.-C. Chou, J.-M. Yeh and Y. Wei, Electrochim. Acta, 2011, 56, 6142-6149.

55 X. Wu, M. Liu, X. Zhong, G. Liu, I. Wyman, Z. Wang, Y. Wu, H. Yang and J. Wang, ACS Sustainable Chem. Eng., 2017, 5, 2605-2613.

56 X. Zhong, I. Wyman, H. Yang, J. Wang and X. Wu, Chem. Eng. J., 2016, 302, 744-751.

57 T.-C. Huang, T.-C. Yeh, H.-Y. Huang, W.-F. Ji, T.-C. Lin, C.-A. Chen, T.-I. Yang and J.-M. Yeh, Electrochim. Acta, 2012, 63, 185-191.

58 X. Sheng, W. Cai, L. Zhong, D. Xie and X. Zhang, Ind. Eng. Chem. Res., 2016, 55, 8576-8585. 
59 G. Qu, F. Li, E. B. Berda, M. Chi, X. Liu, C. Wang and D. Chao, Polymer, 2015, 58, 60-66.

60 F. Li, M. Zhou, J. Wang, X. Liu, C. Wang and D. Chao, Synth. Met., 2015, 205, 42-47.

61 M. Inagaki, Carbon, 2012, 50, 3247-3266.

62 K.-C. Chang, M.-H. Hsu, H.-I. Lu, M.-C. Lai, P.-J. Liu, C.-H. Hsu, W.-F. Ji, T.-L. Chuang, Y. Wei and J.-M. Yeh, Carbon, 2014, 66, 144-153.

63 L. Jianguo, G. Gaoping and Y. Chuanwei, Electrochim. Acta, 2005, 50, 3320-3332.
64 S. Shreepathi, S. M. Naik and M. R. Vattipalli, J. Coat. Technol. Res., 2012, 9, 411-422.

65 C. Zhu, R. Xie, J. Xue and L. Song, Electrochim. Acta, 2011, 56, 5828-5835.

66 K. Cai, S. Zuo, S. Luo, C. Yao, W. Liu, J. Ma, H. Mao and Z. Li, RSC Adv., 2016, 6, 95965-95972.

67 J. Lei, Y. Hu, Z. Liu, G. J. Cheng and K. Zhao, ACS Appl. Mater. Interfaces, 2017, 9, 11902-11908. 